\title{
Research and publication ethics in developing countries
}

\author{
Mohan Raj Sharma $M S^{1}$ iD, Namita Ghimire MA $^{2}$ iD \\ ${ }^{1}$ Department of Neurosurgery, Institute of Medicine, Tribhuvan University, Kathmandu, Nepal \\ ${ }^{2}$ Ethical Review Monitoring and Evaluation Section, Nepal Health Research Council, Kathmandu, Nepal
}

Date of submission: $15^{\text {th }}$ May 2021

Date of acceptance: $16^{\text {th }}$ August 2021

Date of publication: $1^{\text {st }}$ September 2021

\begin{abstract}
The scientific validity of any project relies heavily on the ethically conducted and published research work. Conducting good quality research and publishing it in a scholarly, peer-reviewed journal is the ultimate dream of any researcher. However if done without any research and publication ethics, the work will be counterproductive. Fortunately, there are several publications on ethics of research and publication guiding an early-stage researcher to follow the underlying principles. Research ethics include upholding the basic ethical principles of human research, namely, respect for persons, beneficence, and justice. Publication ethics involve not committing scientific misconduct, resolving authorship disputes, and avoiding simultaneous submission and duplicate publication. Repercussions of unethical research and publications are often unforgiving. Researchers in developing countries face unique challenges in this regard. However, at no cost should these principles be ignored. This will promote the development of a healthy research and publication culture, so desperately needed in these populations. Researchers, sponsors, ethical boards, publishers, and editors should work hand-in-hand to safeguard the research and publication integrity. In this review, issues surrounding research and publication ethics relevant to developing countries will be discussed.
\end{abstract}

Key words: Developing countries, Nepal, Publication, Research, Scientific misconduct.

\section{Introduction}

"W illiam Summerlin, a dermatologist working in a reputed university Hospital in the United States in 1974 claimed that he was able to successfully transplant skin from black mice (with black melanocytes) to white mice (without melanocytes). He proposed that the melanocytes migrated out of the transplanted tissue to the surrounding tissue producing a grayish patch. It was later found that he actually 'painted the mouse' to get the 'desired result'!"

\section{Access this article online}

Website: https://www.nepjol.info/index.php/NJN

DOI: https://doi.org/10.3126/njn.v18i3.37143

HOW TO CITE

Sharma MR, Ghimire $\mathbf{N}$. Research and publication ethics in developing countries. NJNS. 2021;18(3):3-9.

\author{
Address for correspondence: \\ Prof. Mohan Raj Sharma \\ Professor of Neurosurgery, \\ Director of Research, \\ Institute of Medicine, Tribhuvan University, \\ Kathmandu, Nepal. \\ E-mail: mohanrajsharma@iom.edu.np \\ Phone: +97714412605
}

Copyright (C) 2021 Nepalese Society of Neurosurgeons (NESON)

ISSN: 1813-1948 (Print), 1813-1956 (Online)

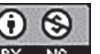

This work is licensed under a Creative Commons Attribution-Non Commercial 4.0 International License.
Research and publication are important in the fabric of a clinician's life. As new diseases occur and existing diseases change course, we need to do research so that we can keep pace with the changing trend. Without research, science soon becomes dead. Although clinical research has made a significant impact in describing the epidemiology, diagnosis, and management of various diseases, it also has some drawbacks. If the research is not carried out with due consideration of ethical principles, it will be a curse rather than a blessing. The description given above serves as the perfect example. This aspect became especially prominent with the beginning and rise of clinical trials (when some patients are asked to take risks of being in the interventional arm), globalization of research, and increasing involvement of pharmaceutical industries. ${ }^{1}$ Ethical conduct of research is largely streamlined in highincome countries (HICs). However, low-income countries (LICs) face unique challenges in ethically conducting and monitoring researcher activities. ${ }^{2,3}$ A systematic review in 2009 suggested that the problem of research and publication misconduct is a worldwide problem including LICs. ${ }^{4}$

For the purpose of this article, ethical principles are broadly divided into two categories: ethics related to research conduct and that related to the publication.

\section{Ethical Issues in Conducting Research}

Clinical research is broadly defined as the systematic collection of data with the intention to make 
it generalizable in humans. ${ }^{5}$ For the purpose of research, the United States Food and Drug Administration (USFDA) defines a human subject as 'an individual who becomes a research participant, either as a recipient of a test article or as a control." ${ }^{\circ} \mathrm{A}$ subset of human subjects is classified as vulnerable (as there may be a decreased decision-making capacity). ${ }^{1,7}$ These include unconscious patients, patients with psychiatric illnesses especially psychosis, pregnant women, children, prisoners, fetuses, intellectually challenged people, etc. Special population refers to a group where voluntary will for participation can be influenced by their status, e.g. students and employees, the junior members of a team, etc. As far as possible no research should be carried out on vulnerable and special populations if the same results can be obtained by doing research on 'normal' subjects. ${ }^{8}$

\section{Concept of Risk}

One important aspect in recruiting participants for research is the concept of risk. ${ }^{9}$ Risk is a 'continuum' rather than an absolute phenomenon. For research, the statement 'no risk no research' holds true. ${ }^{10}$ Especially in randomized trials, some participants are asked to bear the risk of being involved in yet unproven intervention for the result to be conclusive without having any direct benefits to them. ${ }^{1,7,8,10}$ Risks can be broadly classified as minimal and substantial risks. This is the crucial aspect of protocol evaluation by the Institutional Review Committees (IRCs) all over the world. Research with a substantial risk should be carried out, that also with full voluntary participation of the subjects if the results can greatly benefit the society. ${ }^{9,10}$ The vaccine trial against COVID-19 may fall in this category, though risks as such were moderate to the participants. Risks can be physical (procedures on the body), financial (cost of travel, procedures), psychosocial (being identified with disease or condition with great social stigma, e.g. drug abusers, patients with positive HIV status), or legal (study on sex workers). Even asking a sensitive personal question can constitute a risk. ${ }^{11,12}$

Another important aspect to take into consideration is the frequency and magnitude of the perceived risk. How frequent (one in every 10 patients or one in a million) or how big (death or paralysis or loss of appetite for a day) are the potential risks will determine whether such proposals are approved by the national ethical boards or institutional review committees (IRCs). ${ }^{13,14}$

\section{Basic Principles of Research Ethics}

The heart of research ethics is the fact that research participants are not merely utilized as experimental subjects but are treated with utmost respect and dignity, and appropriate privacy is provided as demanded by the nature of the study. Also, throughout the study, all stakeholders- researchers, research sites, IRCs, and funding agencies should safeguard the right and welfare of the participants. ${ }^{8,9,10}$ There are three basic principles of research ethics: respect for persons, beneficence, and justice. ${ }^{6,7,8,10,14,15}$

\section{Respect for Persons (Autonomy)}

Voluntary participation, respect for privacy, and confidentiality are the important components of this principle that make the person autonomous in terms of decision making. Sentence revised

Voluntary participation is ensured by a detailed informed consent process whereby a potential participant is informed of the risks, and benefits of being involved in the study. For this, the researcher should provide as complete information as possible about the project to the participants and their expected role after being enrolled in an unbiased manner. The researcher should explicitly inform that by not being involved in research their treatment will not be affected in any way. If the participant is from a vulnerable group, the consent should be obtained by the appropriate legal guardian.

At every level of research, the participant's privacy should be maintained and their collected information should be kept confidential. This especially holds true if the information obtained is sensitive, e.g. HIV positive status, premarital sex, domestic abuse, etc. If the participants are not convinced of privacy and confidentiality, they will not give true information with the risk of research coming to an erroneous conclusion. Respect is also ensured by the fact that they have the right to withdraw from participation at any time in the research process, including at the time of reporting results.

Researchers should inform the participants of any side effects of intervention, provide adequate management of these side effects, and withdraw them from the research in a timely manner. Also, at the conclusion of the study, every participant has the right to know the results of the research.

\section{Beneficence}

Beneficence is balancing the benefits obtained by the study against the risks and costs involved. The benefits could be to the patients, institutions, society, or all humanity. Every research should at least aim to have beneficence and minimize the risk and have an effective mechanism in place to address adverse events. Research by competent researchers and adequate sample size in the study are other components of justice. Another closely related term is non-maleficence (avoiding the causation of harm). 


\section{Justice}

The principle of justice means that there should be fairness in allocating (or not allocating) experimental treatment to all participants. If we select them based on availability and convenience (students from a campus), or perceived incentives (prisoners will probably not decline participation with the hope that their prison time will be reduced) we are not doing justice. Another aspect of justice is that the study results should be relevant to the population/community participating in the study.

\section{Research Requiring an IRC Approval}

An IRC is an independent committee that reviews the research protocol before the participants are recruited by the researcher. It is extremely important to get review and approval from the IRC before the participants are recruited as approval cannot be given retroactively. The main aim of an IRC is to defend the right and safety of the research participants while facilitating the research. An IRC should ensure that the protocol is technically sound and ethically acceptable.

All research on humans should undergo proper evaluation by a nationally recognized IRC with few exceptions. ${ }^{14}$ Research from publically available data or de-identified data does not require IRC approval. ${ }^{16}$ Such types of studies are exempted from review. Still, permission to use the information from the participants or acknowledgment to the institution from where the data is obtained may be required. ${ }^{16}$ All other types of research undergo either expedited or full board reviews depending on the nature of the risk involved to the participants. There is some controversy regarding the need of requiring IRC approval for case reports. ${ }^{16,17}$ Different institutions may have different regulations in this regard. ${ }^{17}$ As case reports (up to three) do not have the component of generalizability, they do not normally require IRC approval. However, unless absolutely sure, it is best to submit the proposal for evaluation. The IRC will provide a letter of 'exempt' to these kinds of works.

\section{Responsibility for Ensuring Ethical Conduct of Research}

Responsible conduct of research is no one man's game but is a collective responsibility of many. The first and foremost responsibility lies on the investigators. The Principle Investigator (PI) carries the ultimate responsibility of making sure of the fact that all ethical issues are handled well. ${ }^{18}$ Co-investigators facilitate the PI in achieving this goal. The investigators should be familiar with all relevant guidelines of regulatory bodies and be well trained in research ethics. Many sponsoring agencies require all investigators to get a Good Clinical Practice
(GCP) certificate before embarking upon a research project. ${ }^{15}$ Similarly, research institutions (both where the researchers work and where the participants are recruited) should ensure that research is carried out according to ethical principles. Hence, every institution where a sufficient amount of research work is done should have its own IRC. ${ }^{14}$ In places where an IRC does not exist, the Ethical Review Board (ERB) of Nepal Health Research Council (NHRC), the apex body of health research in Nepal, reviews the research directly. ${ }^{19}$ In addition, all externally funded and multicentric studies and all trials go through the ERB of NHRC even if approved by the local IRCs. The other stakeholders are funding agencies. Before sponsoring research, they should ensure that the research is ethically compliant. The fourth and last checkpoints are the journal editors. A scientific journal should not hesitate to reject a manuscript that has ethical issues. Almost all journals these days require a copy of the ethical approval from the IRC before they process the manuscript further. ${ }^{20}$

\section{Dual-use Research}

Dual-use research also called the dual-use research of concern (DURC) is a type of research that is legitimate but has the potential to be exploited for harmful purposes both nationally and internationally. ${ }^{21}$ Genetic sequencing of a virus is a well-known example. Research on pesticides and toxins are additional examples. There are different regulatory requirements for research that fall under this category. ${ }^{22,23}$ LICs should discourage such research as monitoring capability in these countries is weak.

\section{Research in Developing Countries}

Research in developing countries has recently received much attention. ${ }^{24,25,26}$ Every country should strive to get their own data based on which we can safely provide medical care. However, it is not gaining momentum in the right direction. The LICs face two challenges. The first is to promote more research so that more information on health and disease is carried out in this patient population. The second is to carry out research in an ethical manner so that results can be compared with that of HICs. ${ }^{27,28}$ More and more researchers from HICs are showing interest in conducting research in LICs. The reasons are manifold-some good and some bad. Some researchers and organizations have a genuine interest in promoting research in LICs and they should be warmly welcomed. Others may have different motivations and interests; for example, trying to carry out research not relevant to the local population. The third is our own concept and blind mentality of believing the fact that whatever the westerners do must be good. The population of LICs is considered vulnerable as they are financially, 
educationally, and legally disadvantaged.$^{29}$ In many LICs, the ethical review process might be lax giving room for exploitation..$^{28,29,30}$ Since 2017, the NHRC has made it mandatory to have a local PI as a prerequisite for any international research project before it can be carried out in Nepal, a welcome step which was long due. This was largely done to discourage this 'Safari Research.' ${ }^{31}$ To safeguard the interest of the research participants and the local community, some recommendations have been given for research in LICs by the researchers from HICs. ${ }^{30,31}$

1. The research is carried out following the standard international (Declaration of Helsinki, International conference of harmonization, and Good Clinical Practice) and national (NHRC and local IRCs) guidelines.

2. The socio-cultural factors are well respected.

3. There are some benefits to the research participants. For example, after a successful vaccine trial, there should be a provision to offer the vaccine if it turns out to be effective.

4. The proposed research should be relevant to the needs of the community.

5. There should be some benefits to the community once the research is concluded. This may include strengthening the infrastructure to conduct a similar study in the future, training of the local researchers, etc.

\section{Ethical Issues in Publication}

The most scientific and desired method to communicate the results of research is publication in a scientific peerreviewed journal. Publication ethics is emerging as a powerful concept in recent years with the exponential rise of research papers and journals. ${ }^{32,33}$ The Committee on Publication Ethics (COPE) is an international organization of editors and publishers of peer-reviewed journals. It has elaborate guidelines addressing every aspect of ethics in publication. ${ }^{32}$

Scientific misconduct is defined as a behavior by researchers that falls well below the accepted scientific and ethical standards of the scientific community. ${ }^{20,32}$ Though what is acceptable is hard to define, some are obvious and outright culpable. The 'publish or perish' culture in large academia has been a significant contributing factor. ${ }^{34,35}$ Another equally important factor is the excessive zeal to be a scientist celebrity. The sustaining force for unacceptable research is the mushrooming of many predatory journals in LICs. ${ }^{36}$

\section{Serious Forms of Misconduct}

The three most common types of serious research misconduct (often leveled as three cardinal sins) are fabrication (reporting results from data that never existed), falsification (willful manipulation of data; existing data is manipulated to the extent that the results are grossly distorted) and plagiarism (copying of other authors' work without acknowledging them) ${ }^{20,}{ }^{32,}{ }^{37} \mathrm{~A}$ sub-set of plagiarism is self-plagiarism (copying one's previous work without acknowledgments and without getting consent from the copyright owners of the previous publication. ${ }^{37}$

\section{Lesser Forms of Misconduct}

Other lesser degrees of misconducts are conducting research without prior IRC approval, selective reporting, conducting research without informed consent from the participants, not mentioning the side effects of an experimental drug, deliberate wrong use of statistical tests to obtain significant results, gift and ghost authorships, etc. ${ }^{20,32}$ Guest authorship (the name of the prominent individual appearing in publication without any substantial contribution as outlined in authorship criteria by the International Committee of Medical Journal Editors (ICMJE) guidelines to help increase the chance of publication is common in academia whereas ghost authorship (the name of the individual not appearing in the final publication despite having a significant contribution) is common in industry-related publications. ${ }^{38,39}$

\section{Authorship Disputes}

Authorship disputes are not strictly regarded as part of scientific misconduct but deserve mention here as they are fairly common. They can be sensitive and complex to solve as there are substantial grey areas surrounding these issues. ${ }^{20,40}$ At the time of proposal development, the number and the order of authors should be agreed upon by all involved in the research process..$^{20}$ This will serve two purposes. First, the work responsibility can be divided fairly at the outset. Second, it will avoid any hurtful feelings once the article is out. There are no hard and fast criteria as to how many authors can be in a scientific paper. Different journals have different policies regarding the number of 'allowable' authors in a case report. BMJ Case Reports allows a maximum of four authors to be in a case report. ${ }^{41}$ For an original research article, there is no limit provided everyone in the team fulfills the authorship criteria of ICJME. ${ }^{20}$ In the manuscript, excessive selfcitation should be avoided.

\section{Simultaneous Submission and Duplicate Publication}

Simultaneous submission to multiple journals to avoid time lag from submission to publication is another issue..$^{20}$ This is more prevalent in LICs. Though all journals require a mandatory declaration form signed by all authors stating the fact that the manuscript in question is not submitted elsewhere, ignoring this fact is not uncommon. This might lead to duplicate publications with inappropriate weightage for a single research. ${ }^{20,42}$ Prompt retraction of 
the article by the journal should happen as soon as it is detected.

The breach in publication ethics should be addressed at every level by all concerned. Every effort should be made by the scientific community to discourage such activities.$^{43}$ Researchers violating the publication ethics of serious nature (fabrication, falsification, and plagiarism) should be blacklisted whereas those committing a lesser degree of offenses should be cautioned against such activities in the future and should be given an opportunity to correct themselves.

\section{Conclusion}

Research and publication ethics have emerged as powerful subjects of discussion all over the world. Developing countries have the unique challenges of promoting more research pertinent to their needs, at the same time discouraging research with substandard integrity. More work by the concerted efforts of many stakeholders is needed to uplift the standards of research and publication ethics.

\section{Conflict of interest: None Source of support: None}

\section{References}

1. Gallin JI, Ognibene FP, Johnson LL. Principles and practice of clinical research. $4^{\text {th }}$ ed. New York: Elsevier, 2017.824 p.

2. Fathala MF, Fathala MMF. A practical guide for health researchers [Internet]. Cairo, Egypt: World Health Organization, Regional Office for the Eastern Mediterranean: Cairo; 2004 [cited 2021 April 22]. 235 p. Available from: https://applications.emro. who.int/dsaf/dsa237.pdf

3. Sharma MR. Principles of health science research. Kathmandu: Samikchha publications; 2021.164 p.

4. Marus ic A, Bos־njak L, Jeronc`ic A. A systematic review of research on the meaning, ethics and practices of authorship across scholarly disciplines. PLoS ONE. 2001;6(9):e23477. https://doi. org/10.1371/journal.pone.0023477

5. World Health Organization. Health research methodology. A guide for training in research methods [Internet]. $2^{\text {nd }}$ ed. Manila: World Health Organization, Regional Office for the Western Pacific. 2001 [cited 2021 April 23]. 245 p. Available from: https://apps. who.int/iris/handle/10665/206929

6. US Food and Drug Administration.Comparison of FDA and HHS Human Subject Protection Regulations[Internet]. New Hampshire (MD): US Food and Drug Administration; 2000 [cited 2021
April 23]. 7 p. Available from: https://www.fda.gov/ science-research/good-clinical-practice-educationalmaterials/comparison-fda-and-hhs-human-subjectprotection-regulations

7. US Food and Drug Administration. Protection of Human Subjects; Informed Consent; Standards for Institutional Review Boards for Clinical Investigations - [Docket No. 87N-0032] [Internet]. New Hampshire (MD). US Food and Drug Administration; 1998 [updated 2019 April 24, cited 2021 April 26]; [about 6 screens]. Available from: https://www.fda.gov/science-research/clinical-trialsand-human-subject-protection/protection-humansubjects-informed-consent-standards-institutionalreview-boards-clinical\#: :text=Finally $\% 2 \mathrm{C} \% 20$ FDA $\% 20$ proposes $\% 20$ to $\% 20$ add,women $\% 2 C \% 20$ or $\% 20$ mentally $\% 20$ disabled $\% 20$ persons

8. Council for International Organizations of Medical Sciences (CIOMS). International ethical guidelines for biomedical research involving human subjects [Internet]. Geneva: CIOMS; 2002 [cited 2021 April 23]. 60 p. Available from: https://cioms. $\mathrm{ch} /$ publications/product/international-ethicalguidelines-for-biomedical-research-involvinghuman-subjects-2/

9. World Medical Association. WMA Declaration of Helsinki - Ethical Principles for Medical Research Involving Human Subjects [Internet]. du Levant (France). World Medical Association Inc. 1964 [updated October 2013, cited 2021 May 1]. 4 p. Available from: https://www.wma.net/policies-post/ wma-declaration-of-helsinki-ethical-principles-formedical-research-involving-human-subjects

10. World Health Organization. Standards and operational guidance for ethics review of health-related research with human participants [Internet]. Geneva: World Health Organization; 2011 [cited 2021 April 29]. 56 p. Available from: https://www.who.int/ethics/ indigenous_peoples/en/index13.html

11. Phillips, Sarah R. Asking the sensitive question: The ethics of survey research and teen sex. IRB: Ethics \& Human Research. 1994;16(6):1-7. https://doi. org $/ 10.2307 / 3563878$

12. Labott SM, Johnson TP, Fendrich M, Feeny NC. Emotional risks to respondents in survey research. J Empir Res Hum Res Ethics. 2013;8(4):53-66. https:// doi.org/10.1525/jer.2013.8.4.53

13. Wada K, Nisker J. Implications of the concept of minimal risk in research on informed choice in clinical practice. J Med Ethics. 2015;41:804-8. http:// dx.doi.org/10.1136/medethics-2014-102231

14. Department of Health, Education, and Welfare; National Commission for the Protection of Human Subjects of Biomedical and Behavioral Research. The 
Belmont Report. Ethical principles and guidelines for the protection of human subjects of research. J Am Coll Dent. 2014;81(3):4-13. PMID: 25951677

15. World Health Organization. Handbook for Good Clinical Practice. Guidance for implementation (Internet). Geneva: World Health Organization; 2005 [cited 2021 April 13]. 91 p. Available from: https://www.who.int/medicines/areas/quality_safety/ safety_efficacy/gcp $1 . p d f$

16. Neff MJ. Institutional review board consideration of chart reviews, case reports, and observational studies. Respir Care. 2008;53(10):1350-3. PMID: 18811999

17. PandaM,HeathGW, Desbiens NA, MoffittB. Research status of case reports for medical school institutional review boards. JAMA. 2007;298(11):1277-8. https:// doi.org/10.1001/jama.298.11.1277

18. US Food and Drug Administration. Investigator responsibilities: Regulations and clinical trial[Internet]. New Hampshire (MD): US Food and Drug Administration; 2013 [cited 2021 April 24]. 78 p. Available from: https://www.fda.gov/files/ science $\% 20 \% 26 \% 20$ research/published/9-45---1100 -Investigator-Responsibilities- $\%$ E2\%80\%93Regulation-and-Clinical-Trials.pdf

19. Nepal Health Research Council. Ethics/Institutional Review committee [Internet]. Kathmandu; Nepal Health Research Council; 2017 [cited 2021 May 2]. [1 screen]. Available from: http://nhrc.gov.np/ethics/ irc/

20. International Committee of Medical Journal Editors. Recommendations for the conduct, reporting, editing, and publication of scholarly work in medical journals [Internet]. International Committee of Medical Journal Editors; 2019 [cited 2021 May 3]. 19 p. Available from: http://www.icmje.org/icmjerecommendations.pdf

21. Drew TW, Mueller-Doblies UU. Dual-use issues in research - A subject of increasing concern? Vaccine. 2017 Oct;35(44):5990-4. https://doi.org/10.1016/j. vaccine.2017.07.109

22. Miller S, Selgelid MJ. Ethical and philosophical consideration of the dual-use dilemma in the biological sciences. Sci Eng Ethics. 2007;13(4):52380. https://doi.org/10.1007/s11948-007-9043-4.12

23. Atlas RM, Dando M. The dual-use dilemma for the life sciences: Perspectives, conundrums, and global solutions. Biosecur Bioterror. 2006;4(3):276-86. https://doi.org/10.1089/bsp.2006.4.276

24. Rahman MM, Ghoshal UC, Ragunath K, Jenkins G, Rahman M, Edwards C, et al. Biomedical research in developing countries: Opportunities, methods, and challenges. Indian J Gastroenterol. 2020 Jun;39(3):292-302. https://doi.org/10.1007/s12664-

\section{0-01056-5}

25. Challa S, Wu HH, Cunningham BP, Liu M, Patel K, Shearer DW, et al. Orthopaedic trauma in the developing world: Where are the gaps in research and what can be done? J Orthop Trauma. 2018;32 Suppl7:S43-S46. https://doi.org/10.1097/ BOT.0000000000001293

26. Ezeanolue EE, Menson WNA, Patel D, Aarons G, Olutola A, Obiefune M, et al. Nigeria Implementation Science Alliance. Gaps and strategies in developing health research capacity: experience from the Nigeria Implementation Science Alliance. Health Res Policy Syst. 2018;16(1):10. https://doi.org/10.1186/s12961018-0289-x

27. Emanuel EJ, Wendler D, Killen J, Grady C. What makes clinical research in developing countries ethical? The benchmarks of ethical research. J Infect Dis. 2004;189(5):930-7. https://doi. org/10.1086/381709

28. Macpherson CC. Research ethics guidelines and moral obligations to developing countries: Capacitybuilding and benefits. Bioethics. 2019;33(3):389-95. https://doi.org/10.1111/bioe.12577

29. Denny CC, Grady C. Clinical research with economically disadvantaged populations [published correction appears in $\mathrm{J}$ Med Ethics. 2007;33(8):496]. J Med Ethics. 2007;33(7):2-385. https://doi.org/10.1136/jme.2006.017681

30. Nuffield Council on Bioethics. The ethics of research related to healthcare in developing countries [Internet]. London: Nuffield Council on Bioethics;2002 (cited 2021 May 4). 205 p. Available from https://www.nuffieldbioethics.org/publications/ research-in-developing-countries

31. Zumla A, Costello A. Ethics of healthcare research in developing countries. J R Soc Med. 2002;95(6):2756. https://doi.org/10.1258/jrsm.95.6.275

32. Wager E. The Committee on Publication Ethics (COPE): Objectives and achievements $1997-$ 2012. Presse Med. 2012;41(9 Pt 1):861-6. https:// doi.org/10.1016/j.1pm.2012.02.049

33. Equator network. Research ethics, publication ethics and good practice guidelines [Internet]. Oxford: UK Equator center; 2008 [cited 2021 May 4]. [about 2 screens] Available from: https://www.equatornetwork.org/library/research-ethics-publicationethics-and-good-practice-guidelines/18

34. van Dalen HP. How the publish-or-perish principle divides a science: The case of economists. Scientometrics. 2021;126:1675-94. https://doi.org/10.1007/s11192-020-03786-X

35. Desai NG. Why 'publish or perish'? Why not 'publish and prosper'? Perspectives from developing countries. Indian J Psychiatry. 2005;47(1):1-2. 


\section{Research and publication ethics}

https://doi.org/10.4103/0019-5545.46066

36. Grudniewicz A, Mohar D, Cobey KD, Bryson GL, Cukier S, Allen K, et al. Predatory journals: No definition, no defense. Nature. 2019;576:210-2. https://doi.org/10.1038/d41586-019-03759-y

37. Rohwer A, Wager E, Young T, Garner P. Plagiarism in research: A survey of African medical journals. BMJ Open. 2018;8(11):e024777. https://doi.org/10.1136/ bmjopen-2018-024777

38. Schofferman J. Ghost and guest authors: You can’t always trust who you read. Pain Med. 2015;16:41620. https://doi.org/10.1111/pme.12579

39. Gøtzsche PC, Hróbjartsson A, Johansen HK, Haahr MT, Altman DG, Chan AW. Ghost authorship in industry-initiated randomized trials. PLoS Med. 2007;4:e19. https://doi.org/10.1371/journal. pmed.0040019 